\title{
Effects of Various Polyunsaturated Fatty Acids on Blood Cholesterol and Eicosanoids in Rats
}

\author{
Michihiro Sugano, Takahiro IsHIDA and Takashi IDE \\ Laboratory of Nutrition Chemistry, Kyushu University School of Agriculture \\ 46-09, Fukuoka 812, Japan
}

Received March 24, 1986

\begin{abstract}
The hypocholesterolemic efficacy of various polyunsaturated fatty acids was compared in rats given cholesterol-enriched diets with $(0.004 \%)$ or without indomethacin, the cyclooxygenase inhibitor. Evening primrose oil (EPO, linoleic $+\gamma$-linolenic), safflower oil (SFO, linoleic) or soybean oil (SBO, linoleic $+\alpha$-linolenic) were added to diets at the $10 \%$ level. The serum cholesterol level of the EPO group was consistently lower than the other groups and after 3 weeks, it was significantly different from the SFO group without indomethacin and the SBO group with indomethacin. In rats fed EPO, the aorta tended to produce more prostacyclin whereas the concentration of plasma thromboxane $\mathrm{B}_{2}$ was much lower than in rats fed $\mathrm{SFO}$ or $\mathrm{SBO}$. The effects of indomethacin on these eicosanoids were less evident in rats fed EPO. Thus, in addition to the hypocholesterolemic action of $\gamma$-linolenic acid (GLA) in preference to linoleic and possibly $\alpha$-linolenic acid, GLA appears to cultivate an environment suitable for the prevention of carbiovascular disease even in the presence of excess cholesterol in the diet.
\end{abstract}

Available evidence suggests that the hypocholesterolemic effect of linoleic acid is partly, if not entirely, exerted through its conversion to $\gamma$-linolenic acid (GLA), dihomo- $\gamma$ linolenic acid (DGLA), or arachidonic acid (AA). Thus, these metabolites have been found to have cholesterol-lowering action much greater than the parent molecule, linoleic aicd, both in humans ${ }^{1 \sim 3)}$ and experimental animals. ${ }^{4 \sim 6)}$ As the two desaturase systems but not chain elongation steps leading from linoleic acid to AA are largely insufficient in man as compared with rats and mice ${ }^{7)}$ and as the physiological functions of prostaglandins produced from DGLA are shown to be different from those from $A A{ }^{8}{ }^{8}$ the mechanism by which GLA and DGLA manifest the hypocholesterolemic effect may be different from that of AA. The efficacy of the linoleic acid metabolites as a natural protective agent against coronary heart disease may confer benefits by reducing the consumption of linoleic acid, because linoleic acid and hence some prostaglandins of the 2-series are known to act as potent promoters of colon and breast tumors. $^{9 \sim 11)}$

Evening primrose oil (EPO) is practically the sole natural source of GLA and is attracting considerable attention as a hypocholesterolemic agent. ${ }^{12)}$ However, it is still not apparent how GLA manifests its desirable propensity either by itself or through the conversion to specific prostaglandin(s). We have previously observed that the hypocholesterolemic action of EPO is not attributable to its relatively high phytosterol contents but possibly depends on GLA itself. ${ }^{13)}$ In this study, the cholesterol-lowering ability and the levels of several prostaglandins were compared in rats fed high cholesterol diets containing EPO (linoleic $+\gamma$-linolenic), safflower oil (SFO, linoleic), or soybean oil (SBO, linoleic $+\alpha-$ linolenic). Because of the possible contribution of prostaglandins to the hypocholesterolemic action of polyunsaturated fatty acids, the effects of an inhibitor of cyclooxygenase, indomethacin, were also studied. 
Table I. Fatty Acid Compositions and Sterol Contents of Dietary Fats

\begin{tabular}{lrrrrrrc}
\hline \multirow{7}{*}{ Dietary fats } & \multicolumn{9}{c}{ Fatty acids $(\%)$} & Phytosterols \\
\cline { 2 - 6 } & $16: 0$ & $18: 0$ & $18: 1$ & $18: 2$ & $18: 3 \mathrm{n} 3$ & $18: 3 \mathrm{n} 6$ & $(\mathrm{mg} / 100 \mathrm{~g})$ \\
\hline Safflower oil & 6.8 & 1.5 & 13.4 & 75.1 & 2.0 & - & 183 \\
Soybean oil & 10.8 & 3.8 & 23.3 & 54.0 & 7.7 & - & 321 \\
Evening primrose oil & 6.1 & 1.5 & 11.7 & 72.0 & - & 8.2 & 4.3 \\
\hline
\end{tabular}

\section{MATERIALS AND METHODS}

Animals and diets. Male Sprague-Dawely rats (Seiwa Experimental Animals, Fukuoka) were housed individually in the animal room $\left(20 \sim 23^{\circ} \mathrm{C}\right.$, lights on 0800 to 2000 hours) and given experimental diets for 23 days. The composition of the diet was in weight percent; casein 20, fat 10 , mineral mixture 4 , vitamin mixture 1 , choline chloride 0.2 , cellulose 2 , cholesterol $0.5, \mathrm{Na}$-cholate 0.125 , and sucrose to 100 . The mineral and vitamin mixtures defined by Harper ${ }^{14)}$ were purchased from Oriental Yeast Co., Tokyo. There were three groups for dietary fats, EPO, SFO, and SBO and each group was composed of two sub-groups with or without $0.004 \%$ indomethacin. The level of indomethacin adopted has been shown to be effective in inhibiting the synthesis of eicosanoid. ${ }^{15,16)}$ EPO was a gift from Eisai Co., Tokyo and phytosterols were largely removed by silicic acid chromatography ${ }^{13)}$ to prevent their effects on the serum cholesterol level. SBO and SFO were obtained commercially. Fatty acid compositions of dietary fats are shown in Table I. Food intake and body weight were recorded every other day. At times week apart, the rats were deprived of diets at 0830 hours and a small volume of blood was withdrawn from the tail vein at about 1330 1430 hours for enzymatic measurement of serum cholesterol (Cholesterol C-Test, Wako Pure Chemicals Co., Osaka). On the 24th day, rats fasted overnight (1700 0900 hours) were anesthetized with diethyl ether and blood was collected from the abdominal aorta in a syringe containing $3.8 \% \mathrm{Na}_{3}$-citrate $(1 \mathrm{ml}$ for $9 \mathrm{ml}$ blood) and indomethacin (final concentration $10^{-4} \mathrm{M}$ ), and the plasma was separated by centrifugation. The liver, epididymal adipose tissue, and abdominal aorta were immediately excised.

Lipid analyses. Lipids extracted by a mixture of chloroform-methanol $(2: 1, \mathrm{v} / \mathrm{v})$ were analyzed for cholesterol, triglyceride, and phospholipid. ${ }^{17)}$ Liver phosphatidylcholine was separated by thin-layer chromatography ${ }^{18)}$ and the fatty acid composition was assayed by gas-liquid chromatography on a DEGS column. ${ }^{19)}$

Measurement of prostaglandins. Blood plasma was acidified to $\mathrm{pH} 3.0$ with $0.5 \mathrm{~N} \mathrm{HCl}$ and put on a SEP-PAK $\mathrm{C}_{18}$ cartridge (Waters Associates, Milford MA) which had been washed with ethanol and then water. The cartridge was washed successively with water, $15 \%$ ethanol, petroleum ether, and a mixture of petroleum etherchloroform $(65: 35, \mathrm{v} / \mathrm{v})$, and eicosanoids were then eluted with diethyl ether. The solvent was removed under a stream of $\mathrm{N}_{2}$ and the residue dissolved in ethanol. ${ }^{20)}$ The concentration of thromboxane $\mathrm{B}_{2}$ was measured in this alcoholic solution using a commercial radioimmunoassay kit (New England Nuclear NEK-007, Boston MA). Prostaglandins $E_{1}$ and $E_{2}$ were determined using RIA kits (SG 6013 and SG 6001, respectively, Seragen Inc., Boston MA). Immediately after blood withdrawal, the abdominal aorta was excised and the adhering fatty tissues were removed. The aorta (about $1.5 \mathrm{~cm}$ length) was incubated with gentle shaking in $1 \mathrm{ml}$ of Krebs-Henseleit bicarbonate buffer, $\mathrm{pH} 7.4$, at $25^{\circ} \mathrm{C}$ for $30 \mathrm{~min}$. The $\mathrm{pH}$ of the incubation medium was adjusted to 5.0 with $3 \%$ formic acid and eicosanoids were extracted twice with ethyl acetate. ${ }^{21)}$ The extract was dried under a stream of $\mathrm{N}_{2}$ and dissolved in ethanol. 6-Keto-PGF ${ }_{1 \alpha}$ was measured using a New England Nuclear RIA kit (NEK-008). Prostaglandins were all measured in the range around $50 \%$ of the normalized percent bound $\left(B / B_{0}\right)$ for each standard by referring to instruction manuals provided by the suppliers.

Determination of $\Delta^{6}$-desaturase. The $\Delta^{6}$-desaturase activity was measured on liver microsomes using $\left[1-{ }^{14} \mathrm{C}\right]$ linoleic acid (Amersham International plc, Buckinghamshire, England) by the method of Svensson. ${ }^{22}$ )

Statistical analysis. Differences between group means were evaluated by two-way analyses of variance and subsequent $t$ test to confirm the interaction of dietary fats and/or indomethacin. ${ }^{23)}$

\section{RESULTS}

\section{Growth parameters}

Rats weighing on average of $95 \mathrm{~g}, 8$ to 9 rats per group, consumed 17.9 to $20.1 \mathrm{~g}$ /day of diets (average for 23 days) and gained 180 to $203 \mathrm{~g}$ of body weight for 23 days. Neither the type of dietary fats nor indomethacin influenced these parameters. 


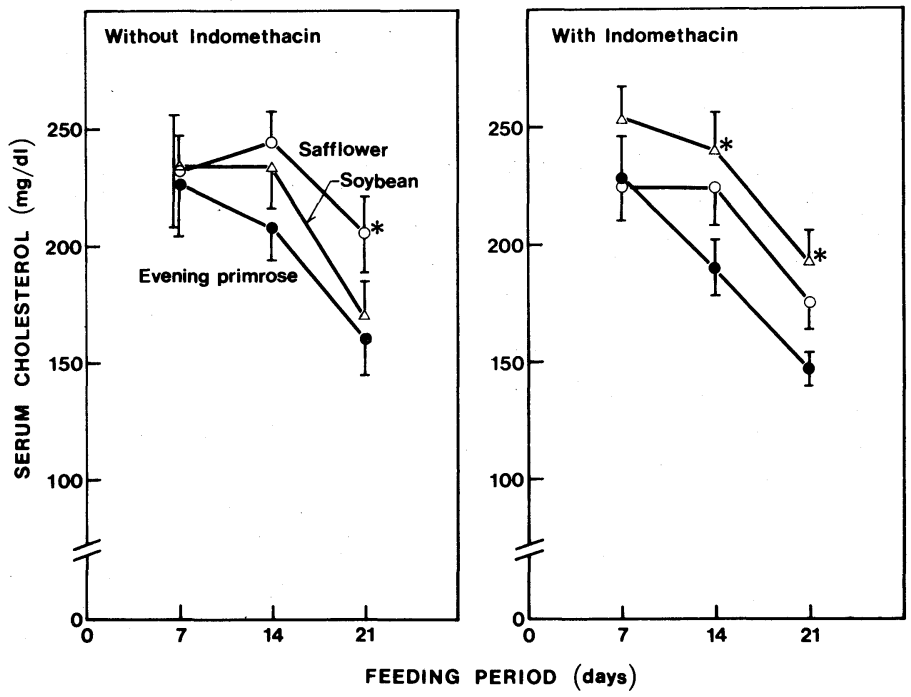

FIG. 1. Effects of Dietary Fats and Indomethacin on Serum Cholesterol Levels.

For experimental details, see MATERIALS AND METHODS. Each point represents mean \pm SE of 8 to 9 rats.

* Significantly different from the corresponding evening primrose oil group at $p<0.05$.

Table II. Effects of Dietary Fats and Indomethacin on the Production of Prostacyclin by Abdominal Aorta and Concentrations of Plasma Eicosanoids

\begin{tabular}{|c|c|c|c|c|c|c|c|c|}
\hline \multirow{3}{*}{ Dietary fats } & \multirow{2}{*}{\multicolumn{2}{|c|}{$\begin{array}{l}\text { Prostacyclin } \\
\text { Indomethacin }\end{array}$}} & \multirow{2}{*}{\multicolumn{2}{|c|}{$\begin{array}{c}\text { Thromboxane } \mathrm{B}_{2} \\
\text { Indomethacin }\end{array}$}} & \multirow{2}{*}{\multicolumn{2}{|c|}{$\frac{\text { Prostaglandin } \mathrm{E}_{1}}{\text { Indomethacin }}$}} & \multirow{2}{*}{\multicolumn{2}{|c|}{$\begin{array}{c}\text { Prostaglandin } \mathrm{E}_{2} \\
\text { Indomethacin }\end{array}$}} \\
\hline & & & & & & & & \\
\hline & None & Added & None & Added & None & Added & None & Added \\
\hline & \multicolumn{2}{|c|}{$(\mathrm{pg} / \mathrm{mg} \text { aorta })^{a}$} & \multicolumn{2}{|c|}{$(\mathrm{pg} / \mathrm{ml})$} & \multicolumn{2}{|c|}{$(\mathrm{ng} / \mathrm{ml})$} & \multicolumn{2}{|c|}{$(\mathrm{ng} / \mathrm{ml})$} \\
\hline Safflower oil & $471 \pm 50$ & $381 \pm 109^{b, c}$ & $512 \pm 143$ & $382 \pm 63$ & $2.7 \pm 0.4$ & $1.2 \pm 0.2$ & $3.4 \pm 0.4^{b}$ & $3.4 \pm 0.3$ \\
\hline Soybean oil & $460 \pm 77$ & $284 \pm 46^{c}$ & $514 \pm 62$ & $336 \pm 92$ & $1.3 \pm 0.2$ & $1.6 \pm 0.2$ & $1.6 \pm 0.2^{c}$ & $2.4 \pm 0.3$ \\
\hline Evening primrose oil & $635 \pm 54$ & $569 \pm 87^{b}$ & $321 \pm 67$ & $379 \pm 76$ & $1.4 \pm 0.2$ & $1.7 \pm 0.3$ & $2.4 \pm 0.3^{c}$ & $2.4 \pm 0.3$ \\
\hline
\end{tabular}

Means \pm SE of 8 to 9 rats per group.

a Measured as 6-keto-PGF ${ }_{1 \alpha}$.

$b, c$ Values in the same column not sharing common superscript letters are significantly different at $p<0.05$.

\section{Serum cholesterol levels}

As shown in Fig. 1, in all groups of rats with or without indomethacin, serum cholesterol levels were initially high and decreased gradually. In general, cholesterol levels were lower in the EPO group than in the SFO or SBO groups, and the difference became statistically significant after 3 weeks; in rats fed diets free of indomethacin EPO showed significantly lower serum cholesterol than those fed SFO, and in rats fed diets containing indomethacin the difference between the EPO and SBO groups was significant.

\section{Liver lipid levels}

Concentrations of liver cholesterol and phospholipid were comparable among the different groups. In contrast, liver triglyceride tended to be higher in rats fed EPO than in those fed SFO or SBO, and the difference observed with diets containing indomethacin was statistically significant, $p<0.05(78.2 \pm$ $9.6,49.0 \pm 6.9$, and $49.7 \pm 7.3 \mathrm{mg} / \mathrm{g}$ (mean \pm $\mathrm{SE})$ for the EPO, SFO, and SBO groups, 
and the corresponding values for the indomethacin-free groups were $67.3 \pm 7.4,49.3 \pm$ 4.4 , and $58.3 \pm 8.3 \mathrm{mg} / \mathrm{g}$, respectively).

\section{Concentration of eicosanoids}

The data for eicosanoids are shown in Table II. In rats fed diets free of indomethacin, the production by aorta of $\mathrm{PGI}_{2}$, measured as 6keto-PGF ${ }_{1 \alpha}$, tended to be greater in the EPO group. In contrast, the level of plasma $\mathrm{TXB}_{2}$ was somewhat lower in the EPO than in the SFO or SBO groups. Concentrations of plasma $\mathrm{PGE}_{1}$ and $\mathrm{PGE}_{2}$ were considerably higher in rats fed SFO than in those fed SBO or EPO, the difference in $\mathrm{PGE}_{2}$ being significant. Indomethancin caused a moderate reduction of the aortic production of $\mathrm{PGI}_{2}$ in the SFO and SBO but not EPO groups. Consequently, the difference was magnified and became significant between the EPO and SBO groups. The plasma level of $\mathrm{TXB}_{2}$ was also decreased by this inhibitor except for the EPO group and hence the difference among the groups disappeared. The effects of indomethacin on the level of $\mathrm{PGE}_{1}$ and $\mathrm{PGE}_{2}$ were variable and the reduction was observed only in the $\mathrm{PGE}_{1}$ level of the SFO group, while the $\mathrm{PGE}_{2}$ level, though the difference was not significant, rather tended to increase in the SBO group. Dietary fat-dependent differences in concentrations of plasma $\mathrm{PGE}_{1}$ and $\mathrm{PGE}_{2}$ were not seen when indomethacin was fed.

TABle III. EFfects of DiETARy Fats AND INDOMETHACIN ON ACTIVITY OF $\Delta^{6}$-DESATURASE OF LIVER Microsomes

\begin{tabular}{|c|c|c|}
\hline \multirow{3}{*}{ Dietary fats } & \multicolumn{2}{|c|}{$\Delta^{6}$-Desaturase activity } \\
\hline & \multicolumn{2}{|c|}{ Indomethacin } \\
\hline & None & Added \\
\hline & \multicolumn{2}{|c|}{$(\mathrm{pmol} / \mathrm{min} / \mathrm{mg}$ protein $)$} \\
\hline Safflower oil & $44.9 \pm 3.7^{a}$ & $59.1 \pm 5.5^{a}$ \\
\hline Soybean oil & $69.2 \pm 9.3^{b}$ & $82.8 \pm 7.8^{b}$ \\
\hline Evening primrose oil & $49.2 \pm 3.6^{a}$ & $52.7 \pm 5.8^{a}$ \\
\hline
\end{tabular}

Means \pm SE of 8 to 9 rats per group.

$a, b$ Values in the same column not sharing common superscript letters are significantly different at $p<0.05$.

Table IV. Effects of Dietary Fats and Indomethacin on Fatty Acid Compositions of Liver Phosphatidylcholine and Adipose Tissue Triglyceride

\begin{tabular}{|c|c|c|c|c|c|c|c|c|c|c|c|}
\hline \multirow{2}{*}{ Dietary fats } & \multirow{2}{*}{ Indomethacin } & \multicolumn{10}{|c|}{ Fatty acids $(\%)$} \\
\hline & & $16: 0$ & $16: 1$ & $18: 0$ & $18: 1$ & $18: 2$ & $18: 3 n 3$ & $18: 3 n 6$ & $20: 3 \mathrm{n} 6$ & $20: 4 \mathrm{n} 6$ & $22: 6 n 3$ \\
\hline \multicolumn{12}{|c|}{ Liver phosphatidylcholine } \\
\hline \multirow[t]{2}{*}{ Safflower oil } & None & 20.7 & 1.8 & 13.1 & $10.4^{a}$ & $22.6^{a}$ & 0.5 & - & $2.9^{a}$ & $21.3^{a}$ & 1.4 \\
\hline & Added & 20.3 & 1.4 & 13.6 & $10.1^{a}$ & $23.1^{a}$ & 0.5 & - & $3.1^{a}$ & $21.1^{a}$ & 1.4 \\
\hline \multirow[t]{2}{*}{ Soybean oil } & None & 20.3 & 1.8 & 13.5 & $11.8^{b}$ & $22.4^{a}$ & 0.7 & - & $3.4^{a}$ & $16.7^{b}$ & 3.1 \\
\hline & Added & 21.3 & 1.6 & 13.1 & $12.4^{b}$ & $21.7^{a}$ & 0.7 & - & $3.6^{a}$ & $17.9^{b}$ & 3.5 \\
\hline \multirow{2}{*}{$\begin{array}{l}\text { Evening } \\
\quad \text { primrose oil }\end{array}$} & None & 21.6 & 1.2 & 12.5 & $9.5^{a}$ & $18.6^{b}$ & - & 0.4 & $5.3^{b}$ & $24.4^{a}$ & 1.1 \\
\hline & Added & 21.6 & 1.7 & 12.5 & $9.3^{a}$ & $19.1^{b}$ & - & 0.5 & $5.9^{b}$ & $23.1^{a}$ & 0.9 \\
\hline \multicolumn{12}{|c|}{ Adipose tissue triglyceride } \\
\hline \multirow[t]{2}{*}{ Safflower oil } & None & 14.0 & 4.2 & 2.8 & $20.1^{a}$ & $52.0^{a}$ & $1.0^{a}$ & - & $0.5^{a}$ & 1.0 & 0.2 \\
\hline & Added & 15.0 & 4.3 & 2.5 & $19.8^{a}$ & $52.7^{a}$ & $1.0^{a}$ & - & $0.4^{a}$ & 1.0 & 0.1 \\
\hline \multirow[t]{2}{*}{ Soybean oil } & None & 15.1 & 4.8 & 2.8 & $27.8^{b}$ & $39.1^{b}$ & $5.0^{b}$ & - & $0.5^{a}$ & 1.1 & 0.4 \\
\hline & Added & 15.8 & 4.8 & 2.8 & $27.9^{b}$ & $39.8^{b}$ & $4.9^{b}$ & - & $0.3^{a}$ & 0.8 & 0.2 \\
\hline \multirow{2}{*}{$\begin{array}{l}\text { Evening } \\
\quad \text { primrose oil }\end{array}$} & None & 13.7 & 4.1 & 2.2 & $17.2^{a}$ & $50.9^{a}$ & - & 3.6 & $1.8^{b}$ & 2.0 & 0.2 \\
\hline & Added & 13.2 & 3.7 & 2.2 & $17.2^{a}$ & $51.9^{a}$ & - & 3.7 & $1.8^{b}$ & 1.8 & 0.2 \\
\hline
\end{tabular}

Means of 8 to 9 rats per group.

$a, b \quad$ Values in the same column not sharing common superscript letters are significantly different at $p<0.05$. 


\section{$\Delta^{6}$-Desaturase activity}

As shown in Table III, the $\Delta^{6}$-desaturase specific activity in the liver microsomes was significantly higher in rats fed SBO than in those fed EPO or SFO regardless of the presence or absence of indomethacin in the diet.

\section{Fatty acid compositions of tissue lipids}

The data shown in Table IV indicated that liver phosphatidylcholine from rats fed EPO contained more DGLA and AA and less linoleic acid than those fed SFO or SBO, thus the ratio of $(20: 3+20: 4) / 18: 2$ was considerably higher in the EPO group. The SBO group contained less AA than the SFO group, and the ratio was somewhat low. Indomethacin had no apparent effects on the fatty acid patterns.

Fatty acid compositions of adipose tissue lipids reflected those of dietary fats. The extent of deposition of $\alpha$-linolenic acid in the adipose tissue appeared to be more greater than that of GLA. The percentage of DGLA and AA tended to be higher in the EPO group.

\section{DISCUSSION}

In our previous study where the phytosterol content of dietary fat was made comparable, the hypocholesterolemic effect of EPO could be ascribed to GLA exclusively in this oil. ${ }^{13)}$ For further confirmation of the hypocholesterolemic action of GLA in EPO, EPO essentially free from phytosterols was used currently. This study, in agreement with experiments done under different conditions, ${ }^{4 \sim 6)}$ showed a hypocholesterolemic effect of GLA in preference to linoleic acid and presumably $\alpha$-linolenic acid, although the effect seemed somewhat more moderate than the results observed elsewhere. ${ }^{13)}$ It seems that the cholesterollowering action of linoleate can be magnified partly through its conversion to GLA and/or further to AA via DGLA. ${ }^{1,24)}$ It is also probable that GLA lowers serum cholesterol faster than does linoleic acid, since the rate of the reduction of cholesterol levels during 1 and 2 weeks was considerably greater in the EPO than in the SFO and SBO groups.

The possibility also exists that a specific prostaglandin of the monounsaturated series (the 1-series PGs), rather than the 2-series PGs, contributes to the cholesterol-lowering action of GLA. Indded, liver phosphatidylcholine from rats fed EPO contained, in addition to AA, almost twice as much DGLA than in those fed SFO, even though the rat can convert linoleic acid to AA efficiently. ${ }^{7)}$ It thus seems likely that when GLA is fed to man, relatively more DGLA may be available since the $\Delta^{5}$-desaturase activity is low in this species. $^{7,25)}$ However, these assumptions could not be sustained from our data, since the level of plasma $\mathrm{PGE}_{1}$, one of the possible candidates for the beneficial effect of GLA, was not higher in the EPO group than in the SFO group. It is, however, plausible that the plasma concentration of $\mathrm{PGE}_{1}$ does not necessarily reflect its effect on cholesterol dynamics due to its rapid degradation.

Alternatively, GLA stimulated the aortic production of $\mathrm{PGI}_{2}$ which may be a potent regulator of cholesferol metabolism. ${ }^{26,27)}$ In addition, the suppressive effect of indomethacin on $\mathrm{PGI}_{2}$ production was much lower in the EPO group, suggesting that GLA cancels the inhibitory action of this inhibitor.

In addition to the beneficial hypocholesterolemic effect, GLA caused a reduction of the concentration of plasma $\mathrm{TXB}_{2}$. From the diverse effects of $\mathrm{TXB}_{2}$ and $\mathrm{PGI}_{2}$ in blood clotting, it seems that EPO, like eicosapentaenoic acid ${ }^{28)}$ plays a role in the prevention of cardiovascular disease, insofar as the effect of GLA on these eicosanoids may not simply be the reflection of the reduced serum cholesterol levels. Again, the effect of indomethacin on the plasma $\mathrm{TXB}_{2}$ was seen only in rats fed SFO or SBO (Table II). The effects of cyclooxygenase inhibitor on plasma concentrations of $\mathrm{PGE}_{1}$ and $\mathrm{PGE}_{2}$ were variable. There is, however, no preferential reason to rule out the possibility that the effect of indomethacin becomes marginal or existing concentrations of prostaglandins already represent the nadir levels as influenced by dietary choles- 
terol. Thus, a similar type of studies using a cholesterol-free diet is required before making definite conclusions.

The specific activity of $\Delta^{6}$-desaturase in hepatic microsomes was significantly higher in rats fed SBO than in any other groups. The result is in contrast with the observation that $\alpha$-linolenic acid is a more preferable substrate for the $\Delta^{6}$-desaturation than linoleic acid $^{25)}$ and it competes with the desaturation of linoleic acid and vice versa. ${ }^{29)}$ As dietary cholesterol interferes with $\Delta^{6}$-desaturation, ${ }^{6,25,29)}$ the complx interplay of these dietary components should also be taken into account. In fact, the fatty acid composition data shows no preferable desaturation of linoleic acid in the SBO group (Table IV) as has been observed elsewhere. ${ }^{30,31)}$ On the while, the fatty acid profile of liver phosphatidylcholine suggested a greater availability of the eicosanoid substrates in rats fed EPO than in those fed SFO or SBO.

In conclusion, GLA as evening primrose oil was effective in lowering serum cholesterol of rats. It seems that GLA in relation to linoleic acid predictably serves as a source of the preferential sustrate for eicosanoids even when the desaturation of polyunsaturated fatty acids is depressed by dietary cholesterol.

\section{REFERENCES}

1) K. J. Kingsbury, D. M. Morgan, C. Aylott and R. Emmerson, lancet, $i$, 1961, 739.

2) D. F. Horrobin and M. S. Manku, Lipids, 18, 558 (1983).

3) A. Szczeklik, R. J. Gryglewski, K. Sladek, E. Kostka-Trabka and A. Zmuda, Thromb. Haemostas. (Stuttgart), 51, 186 (1984).

4) K. Katayasu and I. Yoshikawa, Lipids, 6, 47 (1971).

5) J.-P. Poisson and J. P. Blond, Arch. Int. Physiol. Biochem., 91, 361 (1983).

6) Y. S. Huang, M. S. Manku and D. F. Horrobin, Lipids, 19, 664 (1984).

7) K. J. Stone, A. L. Willis, M. Hart, S. J. Kirtland, P. B. A. Kernoff and G. P. McNicol, Lipids, 14, 174 (1979).
8) A. L. Willis, Lancet, ii, 1984, 679.

9) K. Honn, R. Bockman and L. Marnett, Prostaglandins, 21, 833 (1981).

10) G. M. Kollmorgen, M. M. King, S. D. Kosanke and C. Do, Cancer Res., 43, 4714 (1983).

11) I. B. Vergote, G. M. Laekeman, G. H. Keersmaekers, F. L. Uyttenbroek, J. S. Vanderheyden, G. P. Albertyn, C. F. Haensch, G. J. De Roy and A. G. Herman, Br. J. Cancer, 51, 827 (1985).

12) A. G. Hassam, "The Role of Fats in Human Nutrition," ed. by F. B. Padley and J. Podmore, Ellis Horwood, Chichester, England, 1985, pp. 84 100 .

13) M. Sugano, T. Ide, T. Ishida and K. Yoshida, Ann. Nutr. Metab., 30, (1986), in press.

14) A. E. Harper, J. Nutr., 68, 405 (1959).

15) L. A. Hillyard and S. Abraham, Cancer Res., 39, 4430 (1979).

16) D. L. McCormick, M. J. Madigan and R. C. Moon, Cancer Res., 45, 1803 (1985).

17) Y. Nagata, K. Imaizumi and M. Sugano, Br. J. Nutr., 44, 113 (1980).

18) H. K. Mangold, J. Am. Oil Chem. Soc., 41, 762 (1964).

19) M. Sugano, K. Ryu and T. Ide, J. Lipid Res., 25, 474 (1984).

20) W. S. Powell, "Methods in Enzymology," Vol. 86, ed. by W. E. M. Lands and W. L. Smith, Academic Press Inc., New York, 1982, pp. $467 \sim 477$.

21) G. G. Bruckner, B. Lokesh, B. German and J. E. Kinsella, Thrombosis Res., 34, 479 (1984).

22) L. Svensson, Lipids, 18, 171 (1983).

23) G. W. Snedecor and W. G. Cochran, "Statistical Methods," 6th Ed., Iowa State University Press, Ames, IA, 1967, pp. 472 503.

24) D. F. Horrobin, Rev. Pure Appl. Pharmacol. Sci., 4, 339 (1983).

25) R. Jeffcoat and A. T. James, "Fatty Acid Metabolism and Its Regulation," ed. by S. Numa, Elsevier Science Publishers B. V., Amsterdam, 1984, pp. 85 112.

26) B. B. Weksler, D. P. Hajjar, A. Eldor, D. J. Falcone, K. Tack-Goldman and C. R. Minik, $A d v$. Prostaglandin Thromboxane Res., 11, 463 (1983).

27) W. Krone, P. Kaczmarczk, D. Muller-Wieland and H. Greten, Arterioscl., 4, 534a (1984).

28) J. Dyerberg, J. O. Bang, E. Stofferson, S. Moncade and J. R. Vane, Lancet, ii, 1978, 117.

29) R. R. Brenner, Prog. Lipid Res., 20, 41 (1981).

30) C.-E. Hoy, G. Holman, N. Kaur, I. Byrjalsen and D. Kirstein, Lipids, 18, 760 (1983).

31) Y. S. Huang, D. F. Horrobin, M. S. Manku and J. Mitchell, Proc. Soc. Exp. Biol. Med., 178, 46 (1985). 